\title{
Assessment of Flood Damages and Benefits of Remedial Actions: "What are the Weak Links?"; with Application to the Loire
}

\author{
C. J. De Blois and H. G. Wind \\ University of Twente, Department of Civil Engineering, P.O. Box 217, NL 7500 AE Enschede, \\ The Netherlands
}

Received 10 May 1996; accepted 04 November 1996

\begin{abstract}
Flood damage models are used to determine the impact of measures to reduce damage due to river flooding. Such models are characterized by uncertainty. This uncertainty may affect the decisions made on the basis of the model outcomes. To reduce uncertainty effectively, the most important sources of uncertainty must be found. Uncertainty analysis serves this purpose.

By way of a questionnaire experts were asked about their judgment of the significance of uncertainty sources in flood damage assessment. The results of this questionnaire are compared to an uncertainty analysis by Monte Carlo Simulation, which Torterotot (1993) applied to the French model CIFLUPEDE.

The paper concludes that the role of uncertainty in flood damage assessment is highly significant and cannot be neglected. Both the experts and the analysis on the flood damage assessment model indicate the hydrologic relations 'frequence of occurrence - river discharge - river water level' and the damage estimates as the most important uncertainty sources. For embanked rivers dike breach is the most significant uncertainty source.

A question which appears is, taking into account these uncertainties, to what level of precision can flood damage assessment models predict the expected annual flood damage and the costs and revenues of flood alleviation measures? It is of importance to explore the boundaries of flood damage modeling and to try to find ways to move these boundaries. The uncertainty analysis presented in this paper can be seen as one more step on the way to this goal. Copyright @ 1996 Elsevier Science Ltd
\end{abstract}

\section{Introduction}

Almost every year somewhere in Europe rivers overflow their banks and cause a lot of damage. From December 1993 to January 1994 several European countries experien- ced severe flooding due to heavy rainfall. Total losses in Belgium, France, Germany, Luxemburg, and the Netherlands were estimated at $\$ 900$ million and $\$ 2$ billion if the United Kingdom is included (Ebel and Engel, 1994). In the Netherlands, total losses were about $0.5 \%$ of the Gross National Product. One year later, in January 1995, another case of severe flooding occurred, this time due to a combination of heavy rainfall and meltwater. The estimated total losses in Belgium, France, Germany, Luxemburg, and the Netherlands were less than in 1993: $\$ 700$ million (Ebel and Engel, 1995). In the Netherlands, the dikes were undermined because of the long flood duration. This made it necessary to evacuate 250,000 people from the polder areas behind the dikes.

Different measures can be taken to reduce damage due to flooding of rivers. Before being able to take decisions about what measures to implement, governments must be able to estimate the effect of the proposed measures on the river and its floodplains. Flood damage assessment models are used to determine the impacts of measures on the expected flood damage. Because of lack of data, the natural variation of input data, and the simplifications of the model, the outcomes of such models are characterized by uncertainty. This uncertainty may be that high that it affects the decisions made on basis of the model outcomes (Torterotot, 1993). Therefore, it is useful to find ways to reduce this uncertainty. To reduce uncertainty effectively, the most important sources of uncertainty must be found. In other words: research has to determine the contribution of the different uncertainty sources to the uncertainty in the outcomes, i.e. the expected flood damage. Uncertainty analysis serves this purpose: it is aimed at determining the level of uncertainty in the outcomes and estimating the contribution of the different uncertainty sources.

To analyze the influence of uncertainty in models for flood damage assessment, there is a wide variety of methods for uncertainty analysis available in literature. Morgan and Henrion (1993) give a survey of these methods. 


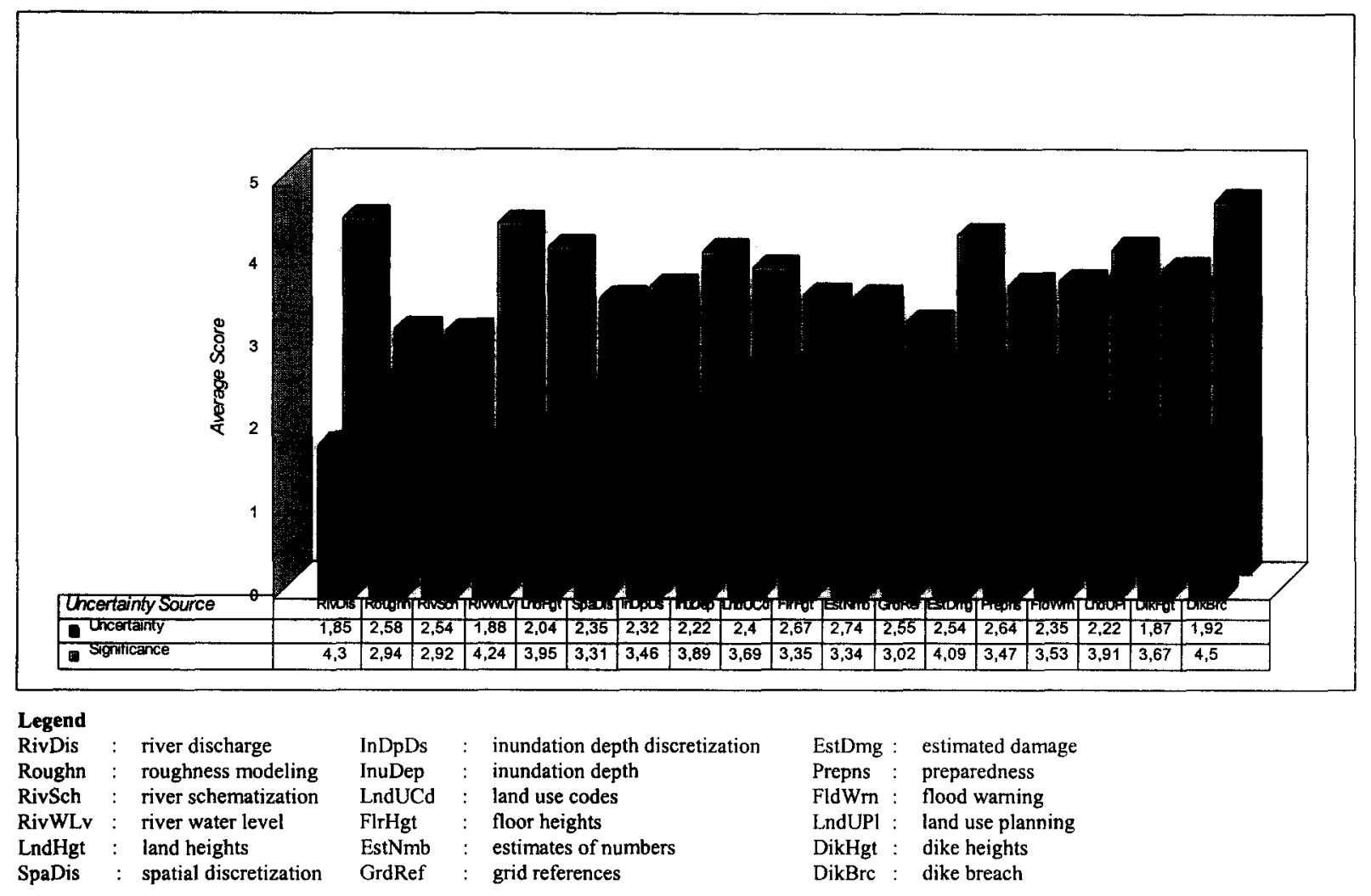

Fig.1. The weighted average significance scores and the average uncertainty scores for a river with dikes. Source: (Blois, 1996).

This paper focuses on the use of the experience and knowledge of experts on the field of flood damage modeling and the use of Monte Carlo Simulation. 96 experts from different European countries were consulted. Torterotot (1993) applied Monte Carlo Simulation to the CIFLUPEDE model, a flood damage assessment model with applications to the Loire. The results of the expert consultation and of the simulation are compared to each other.

Both the study on the Loire and the consultation of experts were carried out within the framework of the European EUROflood project (Penning-Rowsell and Fordham, 1994). The main purpose of this project was to get more insight into the causes and effects of floods and the possible answers in the countries of the European Community. Research institutes from Germany, France, Italy, Portugal, the Netherlands, and the United Kingdom contributed to EUROflood. Various disciplines were represented, such as economics, geography, civil engineering, environmental planning, sociology, and ecology.

The aim of this paper is to identify the most important uncertainty sources in flood damage assessment. Chapter 2 gives the results of the questionnaire. Chapter 3 is about the Loire study and its results. Chapter 4 compares the results of both studies. Finally, Chapter 5 discusses the results acquired and gives some recommendations for further research.

\section{Expert opinion}

In August 1995 a questionnaire was made to form a picture of expert judgment of the significance of uncertain parameters in flood damage assessment. The questionnaire was sent to 96 experts on the area of flood damage assessment in nine European countries. Out of the 96 experts which were consulted, 31 returned the questionnaire.

The questionnaire gives the experts the opportunity to indicate their degree of uncertainty for each answer. The scores for uncertainty thus obtained are used to weigh the answers and compute a weighted mean.

According to the experts, the most significant uncertainty sources are (in order of significance) river discharge, river water level, damage estimates, inundation depth, and land use planning for rivers without dikes, and dike breach, river discharge, river water level, land heights, and damage estimates for rivers with dikes (Blois, 1996). See Fig.1.

Damage estimates is an important uncertainty source. The greatest contribution to uncertainty stems from the following property types: private companies in general, the manufacturing industry in specific, public properties in general, the public buildings and the infrastructure and roads in specific. Estimates of the number of houses contain a lot of uncertainty as well. 
Investigation of the answers of experts with different backgrounds shows that the experts' background is of influence on their answers in some way. The results indicate that the experts with an administrative or economical background give other answers than the experts with a technical background. The question who of the experts is right cannot be answered on the basis of this questionnaire's results. However, it is useful to keep in mind that the experts' background does have influence on their answers.

\section{The Loire study}

Torterotot (1993) designed a computerized model for flood damage assessment on a single sector. The model, with the name 'CIFLUPEDE', was applied to 245 sectors of the Loire river basin (Torterotot, 1993). This locally defined model is subdivided into four submodels, which are linked to each other by input-output relations (See Fig.2.). Geographically the model distinguishes river sections, which are subdivided into sectors. The hydrologic submodel defines the base floods, which are expressed in terms of the river water levels corresponding to the flood intensities considered. The hydraulic submodel determines the inundated area, the inundation level, and the inundation duration for each base flood. The land use submodel defines the distribution of the land use types over the inundated area. Finally, the damage submodel estimates the costs of flooding for each base flood.

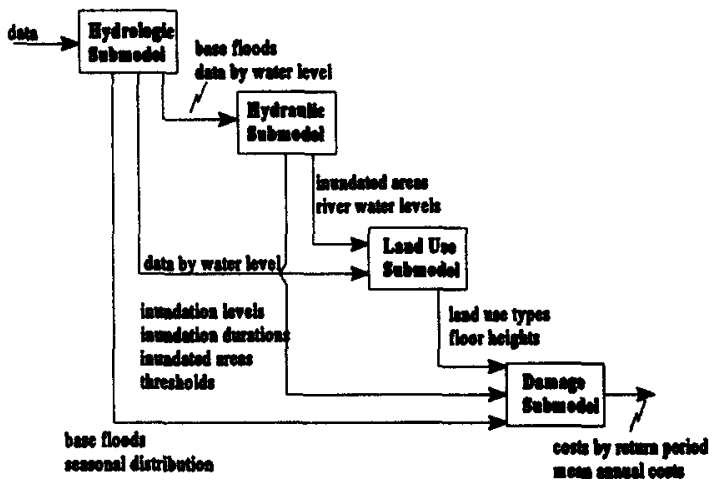

Fig. 2. The structure of CIFLUPEDE.

Torterotot (1993) distinguishes the following eleven categories of uncertainty sources:

- threshold for overtopping (over);

- threshold for the appearance of dike breach risk or certain dike breach (brea);

- threshold for inundation (inun);

- percentages for the spatial distribution of land use types (luse);

- elementary damage functions and seasonal distribution of floods (func);

- inundation level and duration (ledu);
- relations 'return period $T$ - discharge $Q$ - maximum water level $H^{\prime}$ ' (hydr);

- relation $Q-H(h y q h)$;

- relation $T-Q$ or $T-H$ if the discharges are not known (hytq);

- floor beights with respect to natural ground level (floo);

- inundated area (area).

To quantify the contribution of a category of uncertainty sources, the estimated variation $\sigma^{*}$ obtained is compared with all sources of uncertainty to the estimated variation $\sigma$ obtained with all sources except those from that category. The contribution of a certain category $i$ is defined by the following formula:

$\delta \sigma_{i}=\frac{\sigma^{*}-\sigma_{i}}{\sigma^{*}}$

$\boldsymbol{0}$ is represented by either the coefficient of variation (standard deviation divided by mean value) or the mean relative quadratic error. Because leaving out one uncertainty source may enlargen the total estimated variation, the contribution of an uncertainty source, as it is defined above, may be negative.

Torterotot (1993) applied a Monte Carlo analysis to 110 sectors based on 500 random samples of the (categories of) uncertainty sources. During the analysis, the model computes the cost of floods with different return periods and the mean annual costs. Further, Torterotot (1993) makes distinction between sectors with regard to the way in which a sector is inundated in hydraulic sense, e.g by direct inundation ( 65 sectors), or by dike breach (15 sectors).

Fig. 3 shows the contributions of the different categories of uncertainty sources to the uncertainty in the mean annual costs of flooding. The highest contribution is from the hydrologic relations 'return period - river discharge - river water level' (hydr, hyqh, and hytq). Of the non-hydrologic uncertainty sources the damage functions (func) and the inundation level and duration (ledu) have the highest contribution to uncertainty. For some particular sectors it is the uncertainty of the thresholds for dike breach (brea) which mainly contributes to the uncertainty in the costs estimations.

\section{Synthesis}

The experts and the Loire study analyzed the contribution of the different uncertainty sources in the assessment of the mean annual flood damage. Both studies assign a high significance to the hydrologic and hydraulic parameters, i.e. return period, river discharge, river water level, and inundation depth. See Table 1. Further, they both consider the estimates of damage as an important uncertainty 


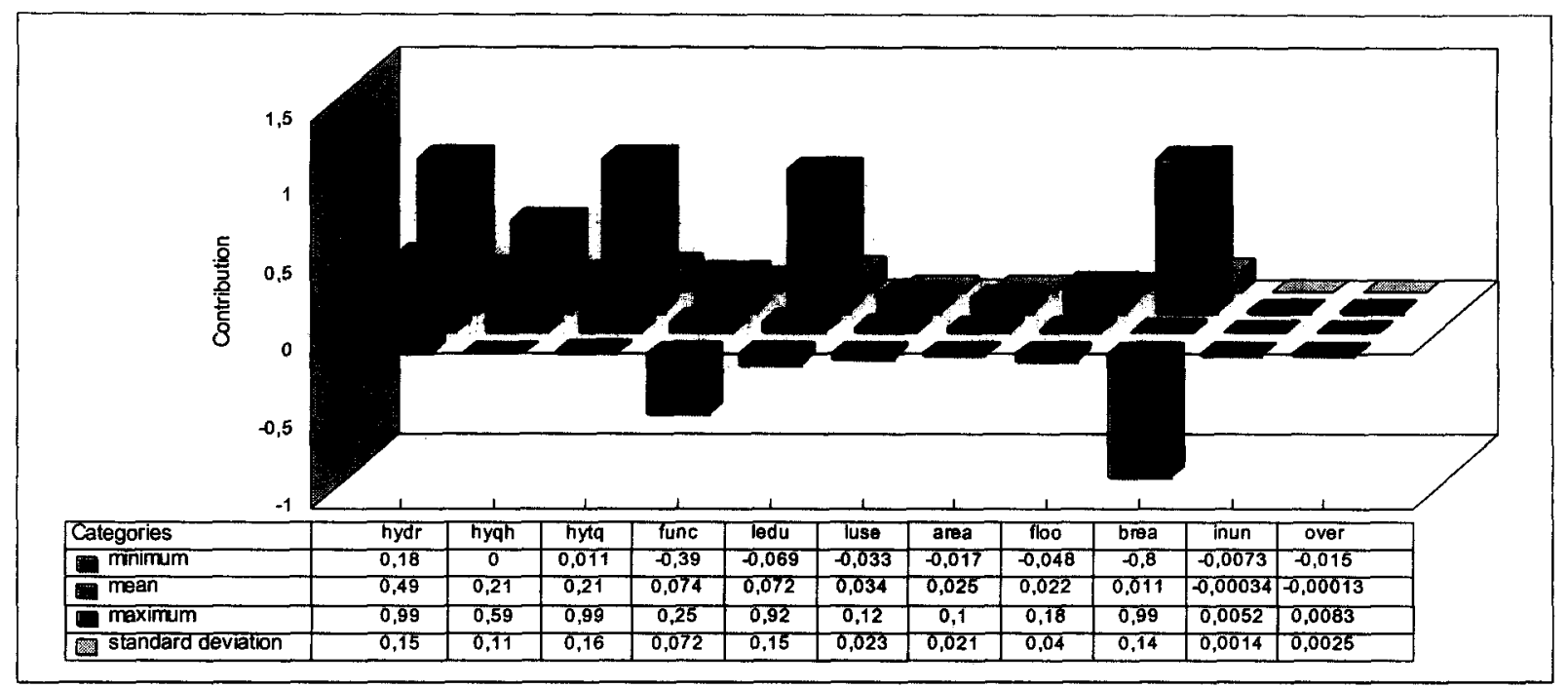

Fig.2. Contributions of the different uncertainty sources to the uncertainty in the mean annual costs for all 110 sectors. Source: (Blois 1996).

factor. In the case of an embanked river the risk of dike breach is (according to the experts) or might be (according to the Loire study, because of the high standard deviation) the most important uncertainty source.

\section{Conclusion}

Both the experts and the Loire study by Torterotot (1993) indicate the hydrologic relations 'frequence of occurrence river discharge - river water level' and the damage estimates as the most important uncertainty sources. For embanked rivers dike breach is the most significant uncertainty source.

This paper restricted itself to flood damage assessment on a local scale. When moving to a regional scale the spatial description of the flood prone area and its economic values and the analysis of spatial coherences are interesting and important issues for research.

As this report shows there is a lot of uncertainties in flood damage assessment. A question which appears is, taking into account these uncertainties, to what level of precision flood damage assessment models can predict the expected annual flood damage and the costs and revenues of flood alleviation measures. It is of importance to explore the boundaries of flood damage modeling and to try to find ways to move these boundaries. The identification of the most important uncertainty sources by using expert opinion or uncertainty analysis on flood damage assessment models can be seen as an important step on the way to this goal.

Table 1. The most important uncertainty sources according to the Loire study and the experts.

\begin{tabular}{|c|c|}
\hline $\begin{array}{l}1 \text { the relation 'return period - river discharge - maximum river water level' } \\
\text { (hydr) } \\
2 \text { the relation 'river discharge - maximum river water level' (hyqh) } \\
3 \text { the relation 'return period - river discharge' (hytq) } \\
4 \text { inundation level and duration (ledu) } \\
5 \text { the elementary damage functions (func) }\end{array}$ & $\begin{array}{ll}1 & \text { river discharge (RivDis) } \\
2 & \text { estimated damage (EstDmg) } \\
3 & \text { river water level (RivWLv) } \\
4 & \text { inundation depth (InuDep) } \\
5 & \text { land use planning (LndUPl) }\end{array}$ \\
\hline the Loire study: river with dikes & the experts: river with dikes \\
\hline $\begin{array}{l}1 \text { the relation 'return period river discharge - maximum river water level' } \\
\text { (hydr) } \\
2 \text { the relation 'return period - river discharge' (hytq) } \\
3 \text { the relation 'river discharge - maximum river water level' (hyqh) } \\
4 \text { the elementary damage functions (func) } \\
5 \text { threshold for dike breach (brea) }\end{array}$ & $\begin{array}{ll}1 & \text { dike breach (DikBrc) } \\
2 & \text { river discharge (RivDis) } \\
3 & \text { river water level (RivWLv) } \\
4 & \text { estimated damage (EstDmg) } \\
5 & \text { land heights (LndHgt) }\end{array}$ \\
\hline
\end{tabular}


Acknowledgement. We would like to thank the experts (See (Blois, 1996).) for completing the questionnaire, and Colin Green, Gilles Hubert, Walter Pflügner, Bartolomeo Reitano, and Joáo Rocha in particular for distributing the questionnaire in their country. We are grateful to Jean-Philippe Torterotot for his inspiring work, which was the basis for an important part of this research. We thank Matthijs Kok and Cees Vreugdenhil for their helpful comments. We render our thanks to Henriëtte Otter and Peter Jasperse for their advises regarding the design and processing of the questionnaire.

\section{References}

Blois, C.J. de, EUROFLOOD. Flood Hazard Assessment and Management. Technical Annex 17: Identification of uncertainty sources in flood damage assessment. University of Twente, Enschede, 1996.

Ebel, U., and Engel, H., The "Christmas floods" in Germany 1993/94. Bayerische Rück, Special issue 16, München, 1994.

Ebel, U., and Engel, H., ...13 months later: The January 1995 floods. Bayerische Rück, Special issue 17, München, 1995.

Morgan, M.G., Henrion, M., Uncertainty: A Guide to Dealing with Uncertainty in Qualitative Risk and Policy Analysis. Cambridge Univer sity Press, Cambridge, 1993.

Penning-Rowsell, E.C., and Fordham, M. (ed), Floods across Europe: Hazard assessment, modeling and management. Middlesex University Press, London, 1994.

Torterotot, J.P., Le coût des dommages dus aux inundations: Estimation et analyse des incertitudes ENPC-CERGRENE, Noisy-le-Grand, 1993. 